\title{
IGF-I and IGF-binding protein-3 measurements on filter paper blood spots in children and adolescents on GH treatment: use in monitoring and as markers of growth performance
}

\author{
U Das, A J Whatmore, J Khosravi ${ }^{5}$, J K H Wales ${ }^{1}$, G Butler ${ }^{2}$, M S Kibirige ${ }^{3}$, A Diamandi ${ }^{5}$, J Jones ${ }^{4}$, L Patel, C M Hall, \\ D A Price and P E Clayton \\ Academic Unit of Child Health, Royal Manchester Children's Hospital, Manchester M27 4HA, UK, ${ }^{1}$ Department of Child Health, Sheffield University, \\ Sheffield S1O 2TH, UK, ${ }^{2}$ Department of Paediatric and Adolescent Endocrinology, Leeds General Infirmary, Leeds LS2 9NS, UK, ${ }^{3}$ Department of \\ Paediatrics, South Cleveland Hospital, Middlesborough TS4 3BW, UK, ${ }^{4}$ Diagnostic Systems Laboratories UK, 77 Heyford Park, Bicester, Oxford \\ OX25 5HD, UK and ${ }^{5}$ Diagnostic Systems Laboratories Canada, Toronto, Ontario M5G 1X5, Canada
}

(Correspondence should be addressed to P E Clayton, Endocrine Science Research Group, Stopford Building, University of Manchester, Oxford Road, Manchester M13 9PT, UK; Email: peter.clayton@man.ac.uk)

\begin{abstract}
Background/aim: In childhood an appropriate response to GH treatment is achieved by titration of growth response against dose administered, with careful observation for side-effects. In order to evaluate the potential use of IGF monitoring in children treated with GH, a cross-sectional study has been carried in 215 children and adolescents (134 with GH deficiency (GHD), 54 with Turner syndrome (TS) and 27 with non-GHD growth disorders) treated with GH for $0.2-13.7$ years.

Methods: IGF-I and IGF-binding protein-3 (IGFBP-3) were measured in ELISAs, using dried capillary blood collected onto filter papers. Results were expressed as the mean S.D. range (SDS). Values of either analyte $<-2$ or $>+2$ SDS were considered abnormal.

Results: IGF-I and IGFBP-3 SDS were higher in the TS and non-GHD groups (mean +0.01 and +0.1 respectively) than in those with GHD (mean value - 0.6). Nineteen per cent of the IGF-I values $(13 \%$ low, $6 \%$ high) and 12\% of IGFBP-3 values were abnormal (10\% low, 2\% high). Abnormalities, either low or high, were most common in the GHD group. There was a weak but significant relationship between change in height SDS over the year up to the time of sampling in the whole group and IGF-I SDS. Satisfactory growth performance $(+0.5>$ change in height SDS $>-0.5)$ was found in those with high $(7.2 \%)$, normal $(60 \%)$ and low (9.3\%) IGF-I levels. Overall, it was estimated that $26 \%$ of the tests would indicate that an adjustment to GH dose (up in 18\% and down in $8 \%$ ) could be considered.

Conclusions: From this cross-sectional study of IGF monitoring across a broad range of diagnoses and ages, it can be concluded that the majority of children on GH have normal levels of IGF-I and IGFBP-3, but $26 \%$ of tests could suggest that a change of GH dose should be considered. Regular monitoring of IGF-I and IGFBP-3 should be considered in any child on GH treatment.
\end{abstract}

European Journal of Endocrinology 149 179-185

\section{Introduction}

The major source of circulating insulin-like growth factor-I (IGF-I) and its principal carrier protein IGFbinding protein-3 (IGFBP-3) is the liver and their synthesis and secretion from the liver is driven predominantly by growth hormone (GH). Children with severe GH deficiency (GHD) or insensitivity have markedly diminished levels of these peptides, and their measurement in serum has an important role in contributing to the diagnosis of GH deficiency/dysfunction in childhood (1). In those children treated with recombinant human $\mathrm{GH}(\mathrm{hGH})$ for a growth disorder, changes in IGF-I and IGFBP-3 over the first year of treatment do not correlate strongly with growth rate $(2-4)$. The monitoring of $\mathrm{GH}$ treatment schedules has primarily involved clinical assessment, including surveillance for side-effects, and measurement of growth as a marker of efficacy. Dose schedules have been based on a per $\mathrm{kg}$ or per $\mathrm{m}^{2}$ basis, adjusted within relatively limited dose ranges.

The situation has been very different in adult GHD replacement regimens, where $\mathrm{GH}$ doses have been titrated against serum IGF-I levels and the occurrence of side-effects (5). Despite a relative paucity of data on the relationship between IGF-I and IGFBP-3 changes and actions of $\mathrm{GH}$ in the GHD adult, it has been proposed that during GH treatment IGF-I levels should be kept within the upper half of the normal range (6). This clinical practice has occurred in parallel with 
population-based studies that have suggested that serum IGF-I levels in the upper quartile of the normal range are associated with an increased risk of certain malignancies $(7-10)$. These associations are strengthened if the concurrent IGFBP-3 level is relatively low (8). Such relationships presumably relate to several decades of exposure to this IGF-I/IGFBP-3 milieu.

Severely GHD children face a lifetime of GH replacement, while other childhood indications for GH such as Turner syndrome (TS) and chronic renal failure are exposed to supraphysiological doses of $\mathrm{GH}$, but only for a few years up to a maximum of 10-15 years. As monitoring of IGF-I is not routinely undertaken, the incidence of abnormal levels and their relationship to IGFBP-3 in children with a range of growth disorders is poorly defined. It has been shown that some children with GHD complete childhood replacement with high levels of both peptides (11).

Routine venepuncture has not been encouraged in our growth clinics. It is now possible to measure IGF-I and IGFBP-3 on blood spots, dried onto filter paper. We therefore conducted a cross-sectional study in all children on $\mathrm{GH}$ treatment to address the following issues: (1) determination of IGF-I and IGFBP-3 levels by assay of filter paper samples, and (2) definition of abnormal IGF status in relation to the growth disorder.

\section{Subjects and methods}

\section{Subjects}

Two hundred and fifteen children, aged $0.7-18.5$ years (115 female, 100 male), from four regional growth clinics were included. All children were on standard GH treatment regimes for growth failure. There was a wide range of diagnoses (Table 1), which for analysis were broadly grouped into those with GHD $(n=134$; 82 male, 52 female), girls with TS $(n=54)$ and those without GHD ( $n=27 ; 18$ male, 9 female). GH treatment had been started at a mean age of 5.2 (range $0.1-16.9$ ) years in the GHD group, $6.8(1.7-15.5)$ years for TS, and $9.9(1.9-13.7)$ years for non-GHD. Other group characteristics are shown in Table 2. Those children with hypopituitarism were on stable hormone replacement regimens, including thyroxine, hydrocortisone, sex steroids and antidiuretic hormone (ddavp).

Drops of capillary blood, obtained from the fingertip in non-fasted conditions, were applied to discrete spots on the filter paper (from Scheiler and Schuell, Keene, $\mathrm{NH}$, USA), allowed to air-dry for $3 \mathrm{~h}$, then stored at $-20^{\circ} \mathrm{C}$. Samples were analysed in two batches.

\section{Methods}

The extraction and assay techniques for measurement of IGF-I and IGFBP-3 have been presented previously (12). In brief for IGF-I, $8 \mathrm{~mm}$ dried blood filter paper discs, punched from the cards, were incubated for $1 \mathrm{~h}$
Table 1 Diagnostic classification within the three treatment groups GHD, TS and non-GHD.

\begin{tabular}{lr}
\hline & $\boldsymbol{n}$ \\
\hline GHD & \\
$\begin{array}{l}\text { Isolated GHD } \\
\quad \text { Idiopathic (with or without hypothalamo-pituitary axis }\end{array}$ & 59 \\
abnormality on MRI) & 2 \\
$\quad$ Associated with syndrome & \\
Hypopituitarism (one or more other pituitary hormone deficits) & 17 \\
$\quad$ Congenital hypopituitarism & 2 \\
$\quad$ Post-head injury & 22 \\
Septo-optic dysplasia & 19 \\
Tumours involving the hypothalamo-pituitary axis & 13 \\
Post-irradiation (cranial or total body) for CNS tumours or & \\
haematological malignancy & 134 \\
Total & \\
TS & \\
Total & 54 \\
Non-GHD & \\
Idiopathic short stature & 7 \\
Intra-uterine growth retardation & 4 \\
$\quad$ Russell-Silver syndrome & 4 \\
Syndromes with growth failure & 6 \\
Skeletal dysplasia & 4 \\
Chronic renal failure & 2 \\
Total & 27 \\
\hline &
\end{tabular}

at room temperature in an extraction buffer (0.005 mol/l Tris, $\mathrm{pH} 7.0$, and $0.5 \mathrm{ml} / \mathrm{l}$ Tween-20). To dissociate IGFs from their binding proteins, this extract was treated first with an acidification buffer $(0.4 \mathrm{~mol} / \mathrm{l}$ glycine-HCl, $\mathrm{pH}$ 2.0), then with the Tris-Tween buffer and finally with a neutralisation buffer (0.85 mol/l Tris and 0.3\% 8-anilino-1-naphthalenesulphonic acid). The acid-neutralised extract was analysed for IGF-I using the Diagnostic Systems Laboratories active ELISA. In brief for IGFBP-3, the discs were incubated with an extraction buffer $(0.05 \mathrm{~mol} / \mathrm{l}$ sodium borate, $\mathrm{pH} 8.5 ; 9.8 \mathrm{~g} / \mathrm{l} \mathrm{NaCl}$; $10 \mathrm{~g} / \mathrm{l} \mathrm{BSA}$; $0.1 \mathrm{~g} / \mathrm{l}$ thimerosal) for $1 \mathrm{~h}$ at room temperature. The extract was then analysed for IGFBP-3 using the DSL active ELISA.

The IGF-I and IGFBP-3 ELISAs are non-competitive and involve horseradish peroxidase-labelled detection antibody. Both assays incorporate a 100-fold sample pre-treatment dilution factor. Intra- and interassay coefficients of variation (CVs) were $5.4-8.5 \%$ and $5.3-16.7 \%$ for IGF-I and $8-8.7 \%$ and $4.7-11.7 \%$ for IGFBP-3.

Comprehensive validation of the extraction procedure from the dried blood spot, the stability of filter card samples and the correlation between dried blood spot IGF-I and IGFBP-3 levels versus matched plasma and whole blood samples using the ELISAs have been presented previously (12).

\section{Statistical methods}

For data analysis, standard deviation scores for IGF-I and IGFBP-3 were calculated. Normative data on 782 children (408 male, 374 female), aged 0-18 years, 
Table 2 Anthropometric data, presented as mean (S.D.) or median, range, in the three treatment groups.

\begin{tabular}{llll}
\hline Variables & \multicolumn{1}{c}{$\begin{array}{c}\text { GHD } \\
\text { Mean (S.D.) } \\
\text { Median, range }\end{array}$} & $\begin{array}{c}\text { TS } \\
\text { Mean (s.D.) } \\
\text { Median, range }\end{array}$ & $\begin{array}{c}\text { Non-GHD } \\
\text { Mean (s.D.) } \\
\text { Median, range }\end{array}$ \\
\hline Age at start of GH treatment (years) & $5.2,0.1-16.9$ & $6.8,1.7-15.5$ & $9.9,1.9-13.7$ \\
Height SDS at start of GH & $-3.2(1.9)$ & $-3.2(1.5)$ & $-4.1(2.1)$ \\
Duration of GH treatment (years) & $4.2,1-13.8$ & $4.1,0.2-10.7$ & $3.1,1-12.7$ \\
MPH SDS & $-0.26(1.1)$ & $-0.04(1.1)$ & $-0.6(1.1)$ \\
Birth weight $(\mathrm{kg})$ & $3.1,0.9-4.2$ & $2.6,0.6-4.1$ & $2.9,1.2-4.1$ \\
\hline
\end{tabular}

MPH, Mid-parental height.

were only available for serum IGF-I and IGFBP-3 measured by the DSL IRMAs. Raw values, measured from the dried blood spots in the active ELISAs, were therefore converted to IRMA values, using the regression equations shown in Fig. $1 \mathrm{~A}$ and $\mathrm{B}$. The latter were derived from comparison of IGF-I $(n=55)$ and IGFBP-3 $(n=45)$ concentrations measured directly in both the blood spot ELISA and the IRMA using samples from normal subjects. In the patients the derived IRMA value was then used to generate a SDS, based on the formula: (observed value - mean value
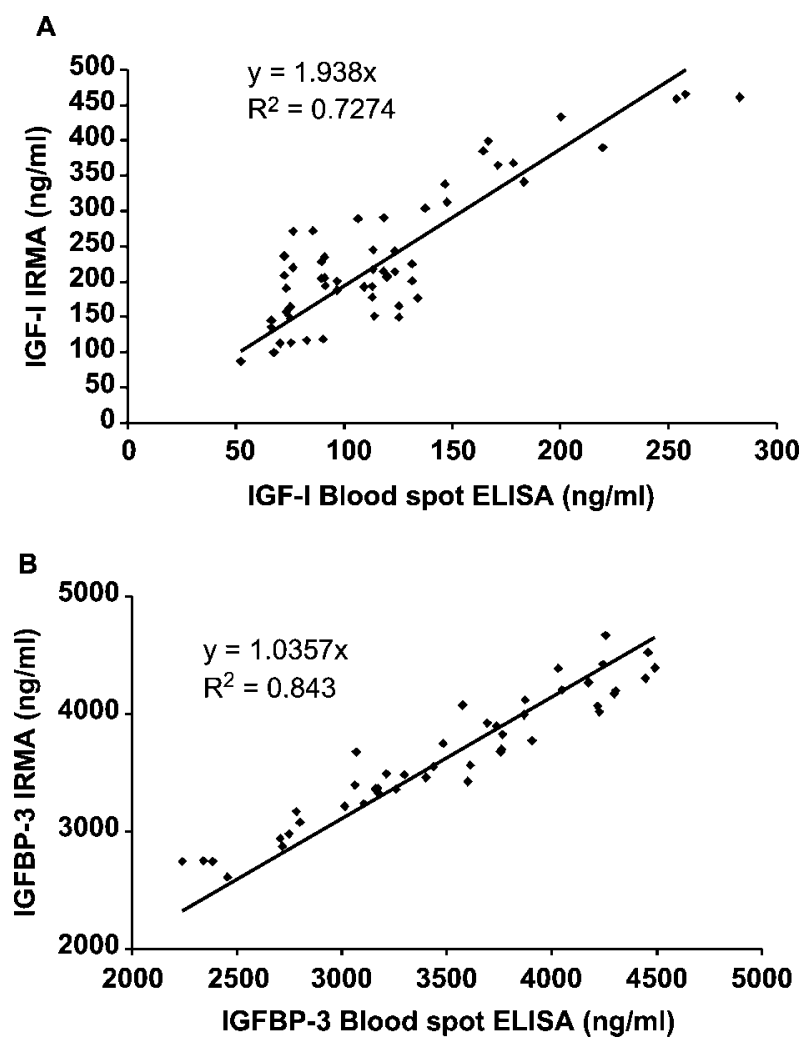

Figure 1 (A) Relationship between serum IGF-I measured by IRMA and blood spot IGF-I measured by ELISA. The regression line has been set to go through zero. The equation was used to convert blood spot IGF-I values in the patients into equivalent serum IRMA values and then into SDS, using the normative data based on the IGF-I IRMA. (B) Relationship between serum IGFBP-3 measured by IRMA and blood spot IGFBP-3 measured by ELISA. The regression line has been set to go through zero. This relationship was used to generate SDS as outlined in (A). for that age and sex $\div$ S.D. around the mean value. SDS $>+2$ or $<-2$ were considered to be abnormal.

Growth data were all expressed as SDS, based on the UK 1990 standards $(13,14)$. In order to compare across treatment groups, these normal standards were also used to convert Turner growth data into SDS. Normally distributed data are presented as mean, S.D. and range. Data with a skewed distribution are presented as median and range. Differences between groups were identified by one-way ANOVA with post hoc testing. Relationships between variables were examined using Spearman's correlation for non-parametric data. Backward logistic regression was used to define those factors having a significant effect on the dependent variable, change in height $(\Delta \mathrm{Ht})$ SDS over the year prior to IGF-I/IGFBP-3 sampling, in GHD, TS and non-GHD groups separately. This regression model includes variables at a significance level of 0.1 .

\section{Results}

In order to generate SDS for the IGF-I and IGFBP-3 data, it was necessary to convert concentrations measured in the ELISA to an IRMA concentration. The relationships between IGF-I and IGFBP-3 measured in the blood spot ELISAs versus the IRMAs are shown in Fig. 1A,B. There are significant correlations between hormone concentrations measured in each assay for IGF-I and IGFBP-3 $(P<0.001)$. However the slope of the relationship between ELISA IGF-I and IRMA IGF-I is 1.94, indicating that the blood spot method gives an IGF-I concentration 50\% lower than the IRMA. In addition, there is variability around the IGF-I regression line. The slope for IGFBP-3 is $\sim 1$ with little variability around the regression line, indicating a close relationship between the two assays.

Anthropometric and biochemical data at the time of sampling are shown in Table 3. There were significant differences between IGF-I as well as IGFBP-3 SDS in the GHD group compared with the TS and non-GHD groups (Table 3). There were large variations in SDS in all groups, but particularly in the GHD group.

The number of abnormal results, as defined by a SDS $<-2$ or $>+2$, in each group is shown in Table 4 . A greater proportion of children had low rather than 
Table 3 Anthropometric and biochemical data at the time of IGF-I and IGFBP-3 sampling. Data are presented as mean (S.D.) or median, range in the three treatment groups.

\begin{tabular}{llll}
\hline Variables & \multicolumn{1}{c}{$\begin{array}{c}\text { GHD } \\
\text { Mean (S.D.) } \\
\text { Median, range }\end{array}$} & \multicolumn{1}{c}{$\begin{array}{c}\text { TS } \\
\text { Mean (S.D.) } \\
\text { Median, range }\end{array}$} & $\begin{array}{c}\text { Non-GHD } \\
\text { Mean (S.D.) } \\
\text { Median, range }\end{array}$ \\
\hline Age (years) & $11.4,0.7-18.5$ & $12.6,2.1-18.2$ & $13.8,3-16.8$ \\
Height SDS & $-1.4(1.4)$ & $-2.4(1.2)$ & $-2.6(1.2)$ \\
BMI SDS & $+0.6(1.5)$ & $+0.4(1.3)$ & $+0.41(1.6)$ \\
$\Delta$ Ht SDS over the year up to sample & $+0.2(0.2)$ & $+0.02(0.4)$ & $+0.2(0.4)$ \\
Dose of GH (mg/m ${ }^{2}$ per day) & $0.8,0.3-1.7$ & $1.1,0.4-1.6$ & $0.9,0.6-1.5$ \\
IGF-I ( $\mu$ g/l) & $107,9-466$ & $161,14-489$ & $213,58-396$ \\
IGF-I SDSף & $-0.6(2.1),-9$ to $+4.4^{*}$ & $+0.01(1.5),-4.6$ to +2.7 & $+0.1(1.8),-5.8$ to +2.4 \\
IGFBP-3 (mg/l) & $3.24,0.76-6.3$ & $4.3,0.92-6.6$ & $4.1,2.98-6.3$ \\
IGFBP-3 SDSף & $-0.7(1.6),-6.8$ to $+2.4^{\dagger}$ & $+0.1(1.1),-3.1$ to +2.2 & $+0.2(1.2),-2$ to +4.6 \\
(IGF-I - IGFBP-3) SDS & $+0.1(1.7)$ & $-0.1(1.1)$ & $-0.1(1.4)$ \\
\hline
\end{tabular}

${ }^{*} P<0.05,{ }^{\dagger} P<0.01 \mathrm{GHD}$ compared with TS and non-GHD. ๆ, mean (S.D.), range.

Table 4 Number and percentage of tests with an abnormal result (IGF-I SDS, IGFBP-3 SDS or both either $<-2$ or $>+2$ ). Percentages with low or high values in each of the three treatment groups are also shown.

\begin{tabular}{|c|c|c|}
\hline & $\begin{array}{c}\text { SDS }<-2 \\
\text { Number (\% of total group) } \\
\text { (\% GHD:TS:Non-GHD) }\end{array}$ & $\begin{array}{c}\text { SDS }>+\mathbf{2} \\
\text { Number (\% of total group) } \\
\text { (\% GHD:TS:Non-GHD) }\end{array}$ \\
\hline IGF-I & $\begin{array}{l}29(13 \%) \\
(79: 7: 14 \%)\end{array}$ & $\begin{array}{c}12(6 \%) \\
(50: 33: 17 \%)\end{array}$ \\
\hline IGFBP-3 & $\begin{array}{l}21(10 \%) \\
(86: 14: 0 \%)\end{array}$ & $\begin{array}{c}4(2 \%) \\
(50: 25: 25 \%)\end{array}$ \\
\hline Both IGF-I and IGFBP-3 & $\begin{array}{c}11(5 \%) \\
(91: 9: 0 \%)\end{array}$ & $\begin{array}{c}3(1 \%) \\
(33.3: 33.3: 33.3 \%)\end{array}$ \\
\hline (IGF-I - IGFBP-3) & $\begin{array}{c}27(13 \%) \\
(30: 15: 55 \%)\end{array}$ & $\begin{array}{c}12(6 \%) \\
(83: 17: 0 \%)\end{array}$ \\
\hline
\end{tabular}

high values, and abnormalities were commoner in IGF-I than in IGFBP-3. All abnormalities were commoner in the GHD group. Only $6 \%$ of children had a similar abnormality in both IGF-I and IGFBP-3 (5\% both low, $1 \%$ both high).

In all patients, analysis of the distribution of height increments compared with normal or abnormal IGF-I values demonstrated the discordance between IGF-I values and growth performance (Fig. 2). Maintenance growth $(+0.5>\Delta$ Ht SDS $>-0.5)$ could occur with low, normal or high IGF-I values, while a normal IGF-I value was most commonly seen in those with catch-up growth $(\Delta \mathrm{Ht}$ SDS $>+0.5)$. Poor growth was relatively rare in this GH-treated cohort, and was usually accompanied by a normal IGF-I SDS. Importantly, however, there were no children with poor growth yet an abnormally high IGF-I SDS.

IGF-I SDS correlated strongly with IGFBP-3 SDS in all groups (Table 5). IGF-I and IGFBP-3 SDS correlated with height SDS at the time of sampling only in the GHD group (Table 5). There was a weak but significant correlation between the change in height SDS over the year prior to sampling and IGF-I SDS $(r=+0.28$, $P=0.003)$ and (IGF-I - IGFBP-3) SDS $(r=+0.23$, $P=0.03)$ only in the GHD group.

In multiple regression, the determinants of change in height SDS over the year prior to sampling and the variability accounted for differed for each group (Table 6). GH dose (as $\mathrm{mg} / \mathrm{m}^{2}$ per day) was a significant determinant only in GHD. (IGF-I - IGFBP-3) SDS was a positive determinant in GHD and non-GHD groups but not in the TS group. However IGFBP-3 SDS as a single variable had a positive influence in GHD but a negative influence in non-GHD. In TS, $\Delta H$ t SDS was correlated inversely only to time on GH treatment.

\section{Discussion}

Monitoring of IGF-I and IGFBP-3 during GH treatment in childhood and adolescence has been recommended in the consensus statement from the GH Research Society, citing safety and assessment of compliance as a rationale for their use (1). There are, however, very few reports of systematic monitoring of the IGF axis on $\mathrm{GH}$, and therefore the evidence base for such tests in children is lacking. The largest data collection of this kind has been published recently showing IGF-I, IGFBP-2 and -3 levels measured three times over the first year of GH treatment and annually over the next 3 years in both GHD and non-GHD children (15). Significant proportions of non-GHD children (20$41 \%$ ) had high IGF-I and IGF-I/IGFBP-3 levels, while $31 \%$ of pre-pubertal GHD children had low IGF-I 


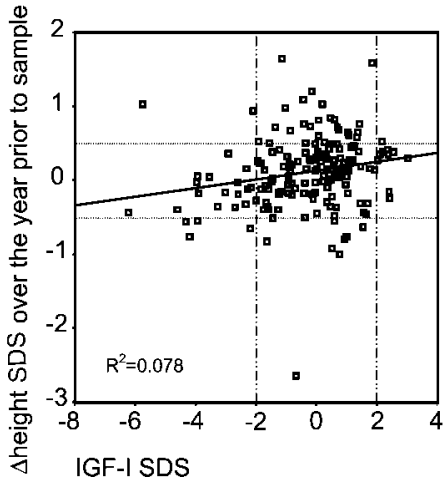

\begin{tabular}{|c|c|c|c|c|}
\hline \multirow{2}{*}{ 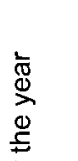 } & & \multicolumn{3}{|c|}{ IGF-I SDS } \\
\hline & & $<-2$ & $\begin{array}{l}>-2 \text { to } \\
<+2\end{array}$ & $>+2$ \\
\hline$\stackrel{\circ}{\partial} \underline{0}$ & $<-0.5$ & $4(2.3)$ & $9(5.2)$ & 0 \\
\hline 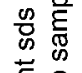 & $\begin{array}{l}<-0.5 \text { to } \\
<+0.5\end{array}$ & $16(9.3)$ & $104(60)$ & $12(7.2)$ \\
\hline 몽 & $>+0.5$ & $2(1)$ & $25(14.4)$ & $1(0.6)$ \\
\hline
\end{tabular}

Figure 2 Left panel: relationship between IGF-I SDS while on GH treatment in all patients (GHD, TS and non-GHD) and $\Delta$ Ht SDS over the year leading up to the monitoring sample. Dotted lines are set at $\Delta \mathrm{Ht}$ SDS of +0.5 and -0.5 . Dot/dashed lines are set at IGF-I SDS of +2 and -2 . Right panel: numbers of subjects (and \% of whole group) in each part of the graph defined by $\Delta \mathrm{Ht}$ SDS ( $<-0.5$, $>-0.5$ to $<+0.5,>+0.5)$ and IGF-I SDS $(<-2,>-2$ to $<+2,>+2)$. A change in the GH treatment schedule (increase for $1-3$, decrease for 4 and 5) could be considered for: (1) the 13 children with slow growth and low or normal IGF-I SDS, (2) the 16 children with normal growth but low IGF-I SDS, (3) the two children with good growth and low IGF-I SDS, (4) the 12 children with normal growth and high IGF-I SDS, and (5) the one child with good growth and high IGF-I SDS.

Table 5 Correlation analysis in the three treatment groups.

\begin{tabular}{|c|c|c|c|c|c|}
\hline Correlation & & & GHD & TS & Non-GHD \\
\hline \multirow[t]{4}{*}{$\Delta \mathrm{Ht}$ SDS over the year to sample } & vs & IGF-I SDS & $r=+0.28, P=0.003$ & NS & NS \\
\hline & vs & IGFBP-3 SDS & NS & NS & NS \\
\hline & vs & (IGF-I - IGFBP-3) SDS & $r=+0.23, P=0.03$ & NS & NS \\
\hline & vs & $\mathrm{GH}$ dose $\left(\mathrm{mg} / \mathrm{m}^{2}\right.$ per day $)$ & NS & $r=-0.43, P=0.006$ & NS \\
\hline$\Delta \mathrm{Ht}$ SDS during $\mathrm{GH}$ treatment & vs & $\mathrm{GH}$ dose $\left(\mathrm{mg} / \mathrm{m}^{2}\right.$ per day $)$ & $r=+0.25, P=0.02$ & NS & NS \\
\hline IGF-I SDS & vs & IGFBP-3 SDS & $r=+0.6, P=0.001$ & $r=+0.67, P<0.001$ & $r=+0.72, P<0.001$ \\
\hline IGF-I SDS & vs & Height SDS at sample & $r=+0.35, P=0.001$ & NS & NS \\
\hline IGFBP-3 SDS & vs & Height SDS at sample & $r=+0.3, P=0.001$ & NS & NS \\
\hline
\end{tabular}

Table 6 Backward logistic regression examining the effect of independent variables on $\Delta \mathrm{Ht}$ SDS over the year up to the time of IGF-I/ IGFBP-3 sample in the three treatment groups.

\begin{tabular}{|c|c|c|c|c|c|c|c|c|}
\hline \multicolumn{3}{|l|}{ GHD } & \multicolumn{3}{|c|}{ TS } & \multicolumn{3}{|c|}{ Non-GHD } \\
\hline Variable & $\begin{array}{l}\text { Standard } \\
\text { coefficient }\end{array}$ & $P$ value & Variable & $\begin{array}{l}\text { Standard } \\
\text { coefficient }\end{array}$ & $P$ value & Variable & $\begin{array}{l}\text { Standard } \\
\text { coefficient }\end{array}$ & $P$ value \\
\hline $\begin{array}{l}\text { Midparental Height } \\
\text { SDS - height SDS } \\
\text { at sample }\end{array}$ & 0.214 & 0.094 & $\begin{array}{l}\text { Duration of } \\
\text { GH treatment }\end{array}$ & -0.667 & $<0.001$ & Age & -0.733 & 0.05 \\
\hline BMI SDS & 0.292 & 0.016 & & & & Birth weight & 1.59 & 0.008 \\
\hline IGFBP-3 SDS & 0.257 & 0.041 & & & & $\begin{array}{l}\text { Midparental } \\
\text { height SDS }\end{array}$ & 1.317 & 0.006 \\
\hline $\begin{array}{l}\text { GH dose }\left(\mathrm{mg} / \mathrm{m}^{2} \text { per day) }\right. \\
\text { (IGF-I - IGFBP-3) SDS }\end{array}$ & $\begin{array}{l}0.225 \\
0.337\end{array}$ & $\begin{array}{l}0.063 \\
0.007\end{array}$ & & & & $\begin{array}{l}\text { IGFBP-3 SDS } \\
\text { (IGF-I - IGFBP-3) SDS } \\
\text { Midparental height } \\
\text { SDS - height SDS } \\
\text { at start of GH }\end{array}$ & $\begin{array}{c}-0.693 \\
1.53 \\
-1.08\end{array}$ & $\begin{array}{l}0.046 \\
0.02 \\
0.018\end{array}$ \\
\hline \multicolumn{3}{|c|}{ Model $r=0.45, P=0.012$} & \multicolumn{3}{|c|}{ Model $r=0.67, P<0.001$} & \multicolumn{3}{|c|}{ Model $r=0.9, P<0.001$} \\
\hline
\end{tabular}

values. It was proposed that monitoring may guide optimisation of $\mathrm{GH}$ treatment schedules. In contrast, although earlier studies measuring immunoreactive somatomedin found significant increments on $\mathrm{GH}$ therapy in GHD children, a large degree of individual variability in response was noted and correlation to growth rate was poor (16). It is likely that this relatively poor correlation between IGF-I and growth has discouraged routine IGF-I monitoring. This stance is now changing with the emphasis being placed on safety and normalisation of IGF parameters.

The present study extends the observations of Ranke et al. (15) by examining IGF-I and IGFBP-3 levels across a similar broad range of diagnoses but this time over a 
wide age range and duration of $\mathrm{GH}$ treatment. The study reflects a cross-sectional snapshot of IGF status in clinical practice, and allows us to evaluate a range of factors that are influencing the IGF axis while on GH. We had a number of aims for our study: like Ranke et al., we set out to quantify the number of abnormal results within our population. We wanted to assess whether IGF-I and IGFBP-3 reflected prior growth performance across a wide range of ages, and also to utilise the filter paper methodology for peptide measurement. This circumvented the need for full venepuncture and in terms of monitoring procedure might be likened to $\mathrm{HbAlc}$ measurement in diabetes.

It was recognised that the need for conversion of IGF-I and IGFBP-3 concentrations measured in capillary blood to an equivalent IRMA value for SDS calculation is not ideal. This is particularly true for IGF-I measurement where the slope for the ELISA to IRMA measurements was 1.94 with variability around the regression line (Fig. 1A). The same relationship for IGFBP-3 was closer with a slope of 1.04 and little variability around the regression line (Fig. 1B). It was, however, essential to convert the data to SDS, and this was only possible if ELISA values were transformed into IRMA values, for which normative data were available. Despite these reservations, the observed correlations (Table 5: IGF-I vs IGFBP-3, IGF-I vs height SDS, IGF-I vs $\Delta$ Ht SDS) are as predicted, while the range of SDS for IGF-I and IGFBP-3 (Table 3) are consistent with those values reported by Ranke et al. (15). Seventeen per cent of our GHD patients had an IGF-I SDS <-2 (18\% for IGFBP-3), while approximately $23 \%$ of the GHD subjects in the study by Ranke et al. had IGF-I levels $<5$ th percentile (13\% for IGFBP-3). These data would indicate that our IGF-I values are providing an adequate approximation of the true concentration. Nevertheless, our data would argue for the generation of normative data based directly on samples taken onto filter paper and measured in the blood spot ELISA.

Reassuringly, the great majority of tests revealed normal levels of IGF-I and IGFBP-3. Very few abnormally high (defined as $>+2$ SDS) values of IGF-I were found $-4.5 \%$ of the GHD group, $7 \%$ of the TS and non-GHD groups - and even less for IGFBP-3. A higher percentage had low IGF-I values: $17 \%$ for GHD, $15 \%$ for non-GHD but only $4 \%$ for TS. This may reflect relative under-treatment in terms of $\mathrm{GH}$ dose in our GHD population. The data also allow an assessment of the relative amount of IGF-I with respect to IGFBP-3, indicating potential discordance between these two GH-sensitive peptides. However a SDS $>+2$ for (IGF-I - IGFBP-3) was uncommon, occurring in $7.5 \%$ of the GHD group, $4 \%$ of TS and in none of the non-GHD.

Epidemiological studies in adults have associated high IGF-I levels with an increased risk of prostate, lung and breast cancer, and found that these associations strengthen if IGFBP-3 levels are relatively low $(7-10)$.
Although there are no data to indicate how long high IGF-I/low IGFBP-3 values should be present to increase risk, and there is no direct mechanistic link defined, it seems a reasonable clinical principle that IGF-I levels should be kept within the normal range during childhood. A recent report examining the risk of cancer in patients treated with human pituitary $\mathrm{GH}$ between 1959 and 1985 has shown significantly increased risks of death from colorectal cancer and Hodgkin's disease (17). These patients received GH in different regimens to those presently used: $\mathrm{GH}$ was given two or three times per week at a standard dose up to 10 iu for all ages. This would be likely to have generated high peaks of IGF-I in the circulation. This cohort is relatively small $(n=1848)$ and the confidence intervals for mortality risk wide, and its extrapolation to current treatment is uncertain. Nevertheless, this study indicates that monitoring of IGF-I and IGFBP-3 levels in any child treated with GH should be a standard practice.

In the whole group, there was a weak correlation between IGF-I SDS and $\Delta \mathrm{Ht}$ SDS over the previous year (Fig. 2). Although compliance was not formally assessed in this study, it is worth considering how often the IGF-I test might indicate that a change in GH dose should be considered. Only $7.5 \%$ of the whole group was growing relatively poorly, either with a low $(2.3 \%)$ or normal $(5.2 \%)$ IGF-I level. In $10.3 \%$ a low IGF-I was associated with normal or increased growth. In all these cases, GH dose could be increased in order to optimise growth performance. Importantly, we did not find any child with a high IGF-I SDS and poor growth rate. Most children with good growth had a normal IGF-I. It was found that $7.8 \%$ of children had an abnormally high IGF-I associated with either normal or increased growth. It is in this group where a reduction in GH dose might be considered. Thus, in total, $26 \%$ of tests would indicate that an adjustment to GH dose could be made.

GH dose did not correlate in univariate analysis with recent height change in GHD (Table 5), but in multiple regression analysis GH dose, when expressed as $\mathrm{mg}$ per $\mathrm{m}^{2}$ rather than $\mathrm{mg}$ per $\mathrm{kg}$ body weight, was one of a number of variables influencing growth rate (Table 6). This suggests that $\mathrm{GH}$ dosing by surface area may be more appropriate than dosing by body weight. In TS, GH dose was inversely related to growth performance. This is likely to reflect an iatrogenic relationship with the clinician increasing $\mathrm{GH}$ doses in those growing poorly.

In order to determine the relative contribution of the IGF measurements and auxological factors to growth performance, multiple regression was used. IGF-I and IGFBP-3 SDS were used as independent variables alone, as well as in combination. The latter was used to test the hypothesis that a measure of 'bioavailable' IGF-I may be most relevant to growth. It was possible to predict $20 \%$ of the variance in growth over the previous year in GHD, $81 \%$ in non-GHD and $45 \%$ in 
TS. The only significant variable in the latter group was time on GH, as a negative determinant. This reflects the tail off in growth performance with increasing time into GH treatment. In both the other groups, (IGFI - IGFBP-3) SDS appeared as a positive determinant of growth, rather than IGF-I alone, implying that the combination is a more accurate marker of growth. In both groups, IGFBP-3 SDS alone also has an independent influence, positive in GHD and negative in nonGHD. We recognise that both peptides increase in response to $\mathrm{GH}$. In GHD, a preferential increase in IGF-I over that seen for IGFBP-3 is associated with good growth. In non-GHD, growth is enhanced if the IGFBP-3 remains relatively low, implying relative insensitivity of IGFBP-3 to GH.

Additionally, mid-parental height or a derivation thereof is significant in both groups. These terms incorporate a measure of the degree of catch-up still present during the treatment years - the greater the discrepancy from parental heights, the better the growth. $\mathrm{GH}$ dose only featured as a weak correlate for the GHD group. In the non-GHD group, birth weight was associated positively with good growth.

This study sought to provide data on the IGF axis in a broad range of children treated with $\mathrm{GH}$. Considerable work will be required before definitive statements on appropriate levels of IGFs through the years on GH can be made. Nevertheless, we may conclude that (1) the great majority of children on GH have normal levels of IGF-I and IGFBP-3, (2) IGF-I and IGFBP-3 can be measured in dried blood spots, which are a convenient measurement but reference ranges based on this methodology are required before routine use can be recommended, and (3) a parameter that combines data on both IGF-I and IGFBP-3 provides the best marker of growth in multiple regression. It is proposed that regular monitoring of IGF-I and IGFBP-3, for instance annually, be undertaken in addition to routine auxology on all children receiving GH treatment.

\section{Acknowledgements}

A J W was generously supported by Serono UK.

\section{References}

1 GH Research Society. Consensus guidelines for the diagnosis and treatment of GH deficiency in childhood and adolescence: summary statement of the GH Research Society on child and adolescent GH deficiency. Journal of Clinical Endocrinology and Metabolism 2000 85 3990-3993.

2 Tillmann V, Patel L, Gill MS, Whatmore AJ, Price DA, Kibirige MS et al. Monitoring serum IGF-1, IGFBP-3, IGF-1/IGFBP-3 ratio and leptin during growth hormone treatment for disordered growth. Clinical Endocrinology 200053 329-336.
3 Mandel S, Moreland E, Nichols V, Hanna C \& Lafranchi S. Changes in insulin-like growth factor-l (IGF-l), IGF binding protein 3 (IGFBP3), growth hormone binding protein, erythrocyte IGF-I receptors and growth rate during GH treatment. Journal of Clinical Endocrinology and Metabolism 199580 190-194.

4 Kristrom B, Jansson C, Rosberg S \& Albertsson-Wikland K. Growth response to $\mathrm{GH}$ treatment relates to serum insulin like growth factor-l (IGF-l) and IGF-binding protein 3 in short children with various growth hormone secretion capacities. Journal of Clinical Endocrinology and Metabolism 199782 2889-2898.

5 Abs R, Bengtsson B-A, Hernber-Stahl E, Monson JP, Tauber J-P, Wilton P et al. GH replacement in 1034 growth hormone deficient hypopituitary adults: demographic and clinical characteristics, dosing and safety. Clinical Endocrinology 199950 703-713.

6 Drake WM, Coyte D, Camacho-Hubner C, Jivanji NM, Kaltsas G, Wood DF et al. Optimizing growth hormone replacement therapy by dose titration in hypopituitary adults. Journal of Clinical Endocrinology Metabolism 199883 3913-3919.

7 Chan JM, Stampfer MJ, Giovannucci E, Gann PH, Ma J, Wilkinson $\mathrm{P}$ et al. Plasma insulin-like growth factor-l and prostate cancer risk: a prospective study. Science 1998279 563-566.

8 Hankinson SE, Willett WC, Colditz GA, Hunter DJ, Michaud DS, Deroo B et al. Circulating concentrations of insulin-like growth factor-l and risk of breast cancer. Lancet 1998351 1393-1396.

9 Yu H, Spitz MR, Mistry J, Gu J, Hong WK \& Wu X. Plasma levels of insulin-like growth factor-l and lung cancer risk: a case-control analysis. Journal of the National Cancer Institute 199991 $151-156$.

10 Petridou E, Dessypros N, Spanos E, Mantzoros C, Skalkidou A, Kalmanti $\mathrm{M}$ et al. Insulin-like growth factor-l and binding protein-3 in relation to childhood leukemia. International Journal of Cancer $199980494-496$.

11 Johannsson G, Albertsson WK \& Bengtsson BA. Discontinuation of growth hormone $(\mathrm{GH})$ treatment: metabolic effects in GH-deficient and GH-sufficient adolescent patients compared with control subjects. Swedish Study Group for Growth Hormone Treatment in Children. Journal of Clinical Endocrinology and Metabolism $1999 \mathbf{8 4} 4516-4524$.

12 Diamandi A, Khosravi MJ, Mistry J, Martinez V \& GuevaraAguirre J. Filter paper blood spot assay of human insulin-like growth factor l (IGF-l) and IGF-binding protein-3 and preliminary application in the evaluation of growth hormone status. Journal of Clinical Endocrinology and Metabolism 199883 2296-2301.

13 Freeman JV, Cole TJ, Chinn S, Jones PR, White EM \& Preece MA. Cross sectional stature and weight reference curves for the UK, 1990. Archives of Disease in Childhood 19951 17-24.

14 Cole TJ, Freeman JV \& Preece MA. Body mass index reference curves for the UK, 1990. Archives of Disease in Childhood 19951 25-29.

15 Ranke MB, Schweizer R, Elmlinger MW, Weber K, Binder G \& Schwarze CP. Relevance of IGF-1, IGFBP-3, and IGFBP-2 measurements during GH treatment of GH-deficient and non-GH-deficient children and adolescents. Hormone Research 200155 115-124.

16 Dean HJ, Kellett JG, Bala RM, Guyda HJ, Bhaumick B, Posner BI et al. The effect of growth hormone treatment on somatomedin levels in growth hormone-deficient children. Journal of Clinical Endocrinology and Metabolism 198255 1167-1173.

17 Swerdlow AJ, Higgins CD, Adlard P \& Preece MA. Risk of cancer in patients treated with human pituitary growth hormone in the UK, 1959-1985: a cohort study. Lancet $2002360273-277$.

Received 22 October 2002

Accepted 26 May 2003 